\title{
Errata
}

\section{Therapeutic use of an antibiotic-resistant Bifidobacterium preparation in men exposed to high-dose gamma-irradiation}

\author{
V. M. Korschunov, V. V. Smeyanov, B. A. Efimov, N. P. Tarabrina, \\ A. A. Ivanov and A. E. Baranov \\ Journal of Medical Microbiology (1996), 44, part 1, 70-74
}

By request of the second author, the spelling of his last name should now be Smeianov.

\section{Anaerobic bacteria in 118 patients with deep- space head and neck infections from the University Hospital of Maxillofacial Surgery, Sofia, Bulgaria}

\author{
L. Boyanova, R. Kolarov, G. Gergova, E. Deliverska, J. Madjarov, M. Marinov \\ and I. Mitov
}

Journal of Medical Microbiology (2006), 55, part 9, 1285-1289

The legend and some of the column headings of Table 2 on page 1288 are incorrect. The correct table is reproduced below.

Table 2. Resistance patterns of anaerobic isolates from two patients' groups (not treated and empirically treated) with abscess or cellulitis of the head and neck

No. of I, Number of intermediately susceptible isolates; No. of R, number of resistant isolates.

\begin{tabular}{|c|c|c|c|c|c|c|c|c|c|c|}
\hline $\begin{array}{l}\text { Organism } \\
\text { (no. of strains) }\end{array}$ & Agent & \multicolumn{3}{|c|}{ Not treated } & \multicolumn{3}{|c|}{ Empirically treated } & \multicolumn{3}{|c|}{ Total } \\
\hline \multirow{3}{*}{$\begin{array}{l}\text { Bacteroides } \\
\text { fragilis group (7) }\end{array}$} & Amoxicillin & 2 & 2 & 0 & 5 & 5 & 0 & 7 & 7 & 0 \\
\hline & Metronidazole & 2 & 0 & 0 & 5 & 0 & 0 & 7 & 0 & 0 \\
\hline & Clindamycin & 2 & 0 & 2 & 4 & 1 & 1 & 6 & 1 & 3 \\
\hline \multirow{3}{*}{$\begin{array}{l}\text { Prevotella and } \\
\text { Porphyromonas } \\
\text { spp. (49) }\end{array}$} & Metronidazole & 10 & 0 & 0 & 39 & 0 & 0 & 49 & 0 & 0 \\
\hline & Clindamycin & 10 & 0 & 0 & 37 & 2 & 3 & 47 & 2 & 3 \\
\hline & Ampicillin/sulbactam & 10 & 0 & 1 & 33 & 0 & 0 & 43 & 0 & 1 \\
\hline \multirow{2}{*}{$\begin{array}{l}\text { Fusobacterium } \\
\text { species }(15)\end{array}$} & Amoxicillin & 8 & 0 & 1 & 7 & 1 & 2 & 15 & 1 & 3 \\
\hline & Metronidazole & 8 & 0 & 0 & 7 & 0 & 0 & 15 & 0 & 0 \\
\hline \multirow{2}{*}{$\begin{array}{l}\text { Other Gram-negative } \\
\text { anaerobes (8) }\end{array}$} & Clindamycin & 2 & 0 & 0 & 5 & 0 & 0 & 7 & 0 & 0 \\
\hline & Ampicillin/sulbactam & 1 & 0 & 0 & 4 & 0 & 0 & 5 & 0 & 0 \\
\hline
\end{tabular}


Table 2. cont.

\begin{tabular}{|c|c|c|c|c|c|c|c|c|c|c|}
\hline \multirow{2}{*}{$\begin{array}{l}\text { Organism } \\
\text { (no. of strains) }\end{array}$} & \multirow[t]{2}{*}{ Agent } & \multicolumn{3}{|c|}{ Not treated } & \multicolumn{3}{|c|}{ Empirically treated } & \multicolumn{3}{|c|}{ Total } \\
\hline & & $\begin{array}{l}\text { No. of } \\
\text { strains }\end{array}$ & $\begin{array}{l}\text { No. } \\
\text { of } R\end{array}$ & $\begin{array}{l}\text { No. } \\
\text { of I }\end{array}$ & $\begin{array}{l}\text { No. of } \\
\text { strains }\end{array}$ & $\begin{array}{l}\text { No. } \\
\text { of } R\end{array}$ & $\begin{array}{l}\text { No. } \\
\text { of I }\end{array}$ & $\begin{array}{l}\text { No. of } \\
\text { strains }\end{array}$ & $\begin{array}{l}\text { No. } \\
\text { of } R\end{array}$ & $\begin{array}{l}\text { No. } \\
\text { of I }\end{array}$ \\
\hline \multirow{3}{*}{$\begin{array}{l}\text { Gram-positive } \\
\text { anaerobic cocci }(14)\end{array}$} & Metronidazole & 2 & 0 & 0 & 12 & 1 & 0 & 14 & 1 & 0 \\
\hline & Clindamycin & 2 & 0 & 1 & 10 & 0 & 0 & 12 & 0 & 1 \\
\hline & Ampicillin/sulbactam & 2 & 0 & 0 & 12 & 0 & 0 & 14 & 0 & 0 \\
\hline \multirow{3}{*}{$\begin{array}{l}\text { Clostridium } \\
\text { tertium }(1)\end{array}$} & Metronidazole & 0 & 0 & 0 & 1 & 1 & 0 & 1 & 1 & 0 \\
\hline & Clindamycin & 0 & 0 & 0 & 1 & 0 & 0 & 1 & 0 & 0 \\
\hline & Ampicillin/sulbactam & 0 & 0 & 0 & 1 & 0 & 0 & 1 & 0 & 0 \\
\hline \multirow{3}{*}{$\begin{array}{l}\text { Gram-positive } \\
\text { non-spore-forming } \\
\text { rods }(57)\end{array}$} & Metronidazole & 15 & 11 & 0 & 42 & 29 & 0 & 57 & 40 & 0 \\
\hline & Clindamycin & 15 & 1 & 0 & 38 & 2 & 2 & 53 & 3 & 2 \\
\hline & Ampicillin/sulbactam & 15 & 0 & 0 & 41 & 0 & 0 & 56 & 0 & 0 \\
\hline
\end{tabular}

